\title{
Configuração dos cursos superiores de graduação tecnológica em design no Brasil: ênfase no Estado do Rio de Janeiro
}

Configuration of the top design technology courses in Brazil, focusing on Rio de Janeiro's state

SCHNAIDER, Sílvia Helena de carvalho; Doutora; ESDI

silviaschnaider@gmail.com

FREITAS, Sydney Fernandes de; Doutor; ESDI

sydneydefreitas@gmail.com

\section{Resumo}

Este artigo apresenta dados sobre a configuração dos cursos superiores de tecnologia em design no Brasil, com ênfase no Estado do Rio de Janeiro. Fez-se um recorte na tese intitulada "Cursos superiores de graduação tecnológica em design: expansão e contexto atual da oferta no Brasil" (2017). Data da década de 1960 o registro dos primeiros cursos; as Regiões Nordeste e Sudeste foram as pioneiras. Levantaram-se dados através de uma Busca Interativa por Estados e por Nome de Curso "Design, Design Gráfico e Desenho Industrial” no portal do e-MEC, totalizando 357 cursos na área. A Região Sudeste lidera o ranking em quantidade de IES na área. O estado do Rio de Janeiro tem sozinho, 30 cursos: 11 cursos em Design Gráfico, 12 cursos em Design e 7 cursos em Desenho Industrial. As informações foram computadas por região e apresentam-se por meio de gráficos e tabelas.

Palavras Chave: Ensino superior; e-MEC; Graduação tecnológica em design.

\begin{abstract}
This article presents data about the configuration of the top design technology courses in Brazil, focusing on the state of Rio de Janeiro. A thesis was titled "The design courses in Brazil: expansion and actual context " (2017). Data was collected through an Interactive Search by States and by Name of Course "Design, Graphic Design and Industrial Design" in the e-MEC portal, totaling 357 courses in the area. The Southeast Region leads the ranking in amount of HEl in the area. The state of Rio de Janeiro has 30 courses: 11 are named Graphic Design, 12 Design and 7 Industrial Design. The information was computed by region and presented through graphs and tables.
\end{abstract}

Keywords Higher education; e-MEC; Technological graduation in design. 


\section{Introdução}

Este artigo trata da configuração dos cursos superiores de tecnologia em design no Brasil (com destaque para o estado do Rio de Janeiro) e sua expansão recente de cursos e matrículas ofertadas na área. Por meio do levantamento da História da Educação Profissional no Brasil, é possível traçar a trajetória do surgimento das primeiras instituições de ensino no país (Período Monárquico 1808 -1889) até os mais recentes cursos oferecidos atualmente e registrados no portal do Ministério da Educação (MEC).

O levantamento de dados foi feito por meio de uma pesquisa bibliográfica a partir de referências publicadas em artigos, livros, dissertações e teses relacionados ao tema "Educação Profissional no Brasil", com foco nos cursos superiores tecnológicos em design. Foram utilizados documentos publicados pelo governo federal e por instituições de ensino e pesquisa (destaque para o MEC e o INEP), além de faculdades e universidades.

Os dados apresentados decorreram de uma Busca Interativa por Estados e por Nome de Curso - Design/Design Gráfico/Desenho Industrial, realizada em 14 de março de 2016 no sistema eMEC - Cursos como Design de Moda, Design de Interiores, e outros, foram excluídos desta amostra, atendendo ao objetivo de comparar os cursos que apresentassem grades curriculares semelhantes.

Os outros itens da busca ficaram na situação default do sistema, ou seja, não foram assinalados o Município da IES, a Gratuidade do Curso, a Modalidade (à Distância ou Presencial), o Grau (Bacharelado, Licenciatura, Tecnológico e Sequencial), o índice (CC, CPC, ENADE), a nota (1, 2, 3, 4,5 e SC) e a situação (em atividade, em extinção, extinto e sub judice). A operação de busca foi repetida seguidamente três vezes em cada estado do país, sempre na mesma ordem por nome de curso: primeiro, uma busca por curso de nome Design; depois, por nome Design Gráfico; por fim, pelo nome Desenho Industrial. Após o resultado, consideraram-se somente os cursos "em atividade".

Os cursos superiores de graduação tecnológica em design no Brasil são uma realidade há 40 anos e, portanto, fêz-se necessário configurar sua História e entender o seu processo educativo atual. É importante ressaltar que os cursos com grau de bacharelado predominaram no país até meados dos anos 2.000, possuíam carga horária entre 800 e 1.024 horas anuais de trabalho discente e tinham duração mínima de três anos. Já a recente modalidade de tecnólogo como graduação contempla cursos cuja carga horária varia entre 1.600 e 2.400 horas e com duração máxima de três anos. No Brasil, há atualmente 357 cursos superiores na área em atividade, sendo 160 com grau de bacharelado e 199 tecnológicos.

\section{Desenvolvimento}

Os tópicos a seguir indicam a quantidade dos cursos em atividade por região do Brasil, da região que apresenta maior quantidade de cursos à de menor quantidade:

1. Região Sudeste - 53 cursos em Design, 84 cursos em Design Gráfico, 15 cursos em Desenho Industrial e 2 cursos em Design de Produto. Total: 154.

2. Região Sul - 36 cursos em Design, 51 cursos em Design Gráfico, 7 cursos em Desenho Industrial, 1 curso em Design Visual e 1 curso em Design de Produto. Total: 96.

3. Região Nordeste - 20 cursos em Design e 32 cursos em Design Gráfico. Total: 52.

4. Região Norte -8 cursos em Design e 20 cursos em Design Gráfico. Total: 28.

5. Região Centro-Oeste - 4 cursos em Design, 21 cursos em Design Gráfico e 2 cursos em Desenho Industrial. Total: 27. 
Portanto, a maior concentração de cursos está na região Sudeste e a menor encontra-se na região Centro-Oeste. Como se pode perceber, novos nomes de curso estão sendo utilizados para registro no portal e-MEC, como Design Visual e Design de Produto. Estes cursos têm a mesma grade curricular dos antigos cursos denominados Desenho Industrial - Programação Visual e Desenho Industrial - Projeto de Produto.

O nome de curso Design Gráfico apresenta-se em maior quantidade (58\%) do total de cursos na área, o nome Design também possui quantidade expressiva (34\%). Já o nome utilizado para registro desde a década de 1960, Desenho Industrial, tem uma participação menor com, somente, 24 cursos registrados neste nome no portal do e-MEC (7\%). Todos os cursos de nome Desenho Industrial, Design Visual e Design de Produto são no grau bacharelado e na modalidade presencial. Assim como $100 \%$ dos cursos na modalidade à distância são tecnológicos e de nome Design Gráfico.

A seguir, apresenta-se um gráfico que facilita a visualização dos resultados:

Figura 1: Consulta avançada no portal do MEC por: Cursos de Graduação, Nome do Curso (Design, Design Gráfico e Desenho Industrial ) e estado brasileiro (UF).

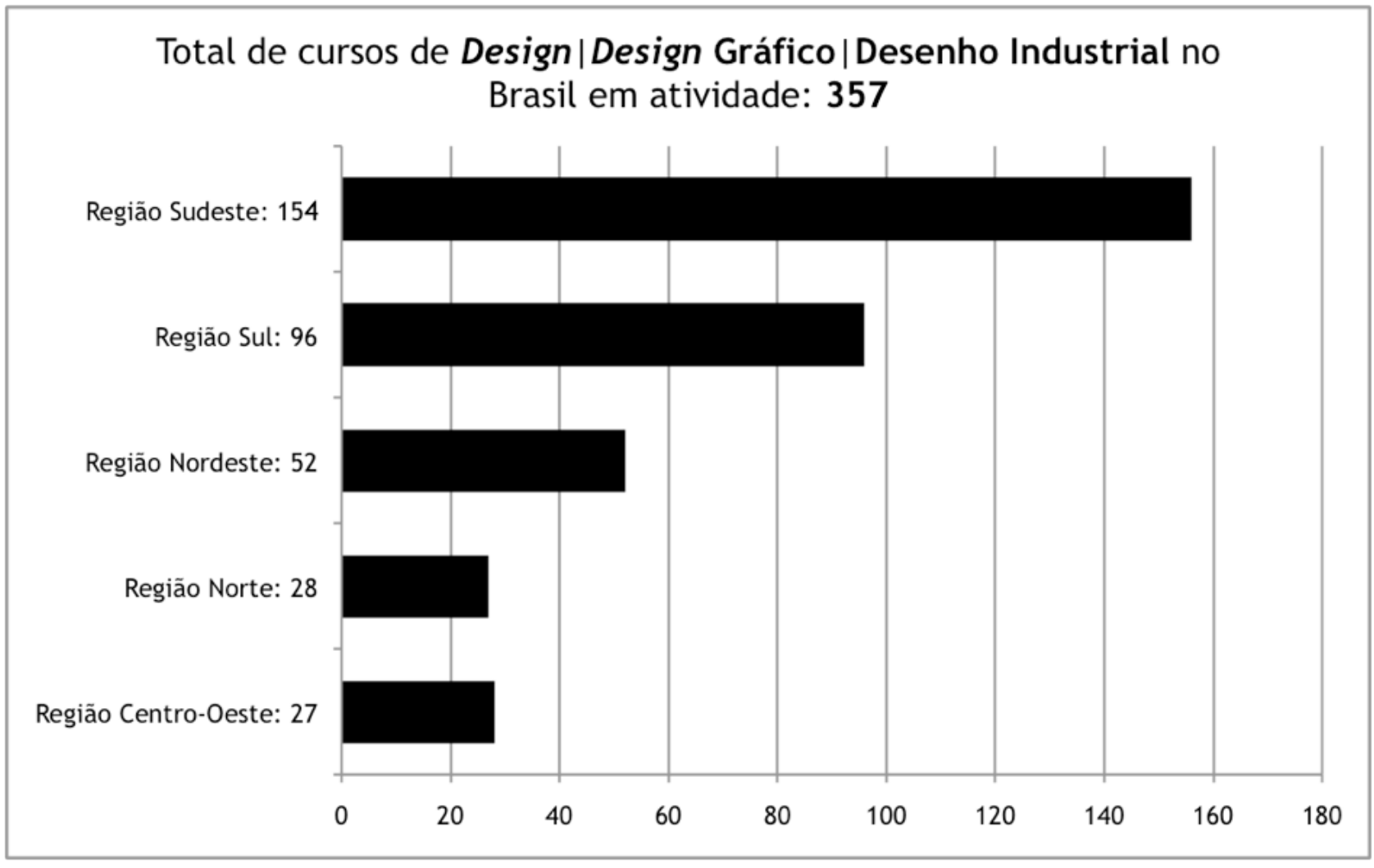

Fonte: portal do MEC.

Ao observar o gráfico, fica evidente que a Região Sudeste tem uma quantidade superior de cursos em face às outras regiões do país e que as regiões Norte e Centro-Oeste dispõe de um número menor. A seguir, apresenta-se um gráfico atualizado que facilita a visualização da realidade brasileira na categoria Grau X IES: 
Figura 2: Gráfico demonstrativo por região do país dos cursos com grau de Tecnológico e Bacharelado.

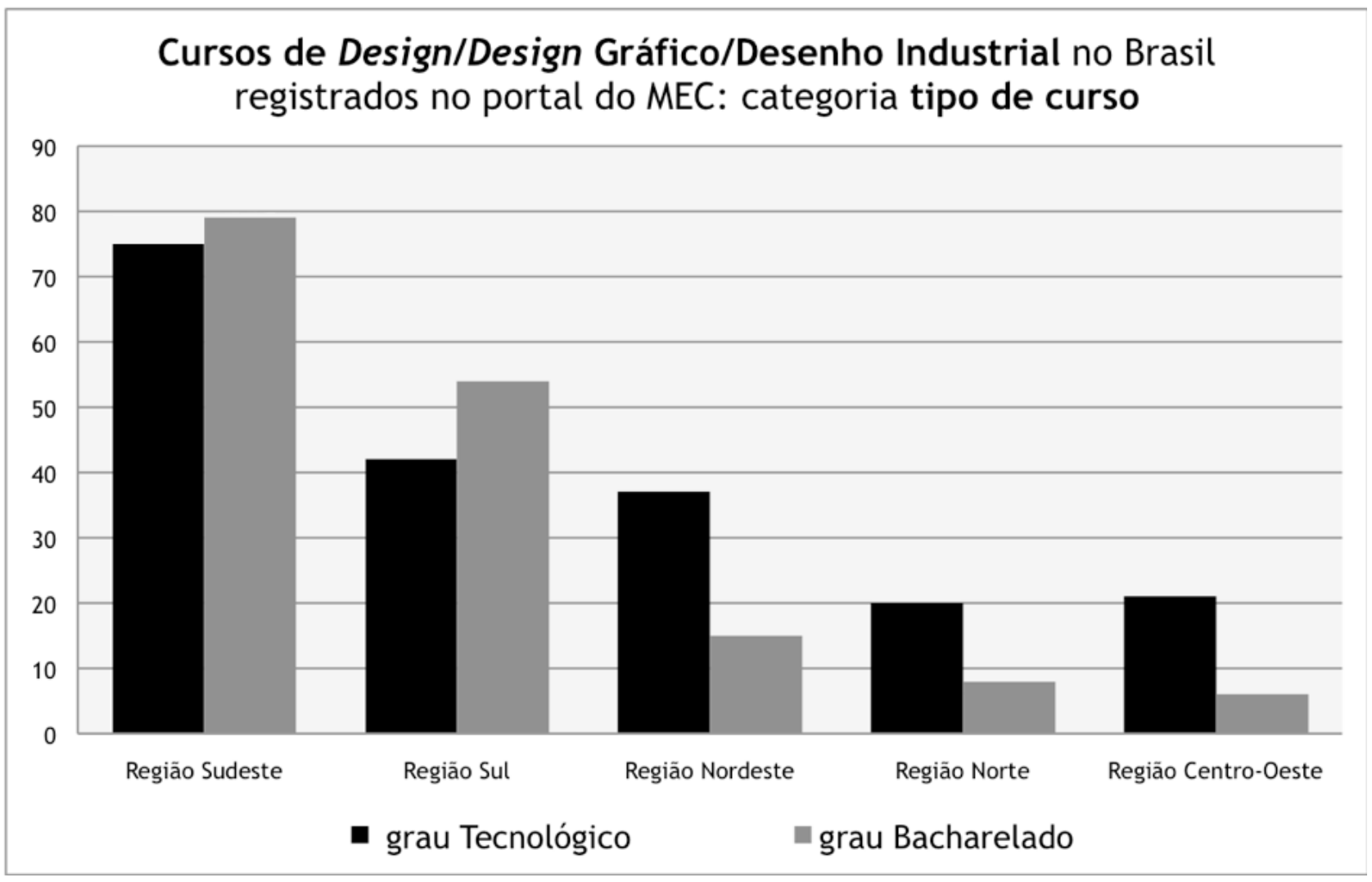

Fonte: portal do MEC.

Percebe-se que, somente na Região Sul, a oferta de cursos tecnológicos em Design é bem menor do que nos outros estados. São 54 cursos no grau bacharelado e 42 no grau tecnológico. Nas regiões Nordeste, Norte e Centro-Oeste os cursos no grau tecnológico têm mais de $50 \%$ em quantidade que os cursos no grau bacharelado. Na Região Sudeste a diferença é mínima, somente 4 cursos no grau bacharelado a mais de um total de 154 . No Brasil, há atualmente $\mathbf{2 8 7}$ cursos na modalidade presencial e $\mathbf{7 0}$ a distância. Todos os cursos com grau de bacharelado são na modalidade presencial, todos os cursos a distância são no grau tecnológico.

A maior concentração de cursos tecnológicos a distância está na região Sul do país (27 cursos), seguida da região Norte (14 cursos). Já a maior concentração de cursos tecnológicos na modalidade presencial está na região Sudeste: São Paulo (46 cursos), Rio de Janeiro (10 cursos), Minas Gerais (11 cursos) e Espírito Santo (1 curso). As Regiões Nordeste e Sudeste possuem as menores quantidades de cursos na modalidade a distância (6 cursos).

\section{Cronologia das IES: 1962-2017}

Em 1999, das 47 instituições que ofereciam cursos com habilitações em Projeto de Produto e Programação Visual, 29 cursos de Graduação em Design estavam concentrados na Região Sudeste do país (quase $60 \%$ dos cursos). Hoje, a situação continua semelhante: dos 357 cursos superiores na área em atividade, 156 localizam-se na Região Sudeste (cerca de 44\% do total).

$O$ registro mais antigo no site do $\mathrm{MEC}$ de uma graduação tecnológica na modalidade 
presencial na área data de 25 de setembro de 2000. O IFPE-Instituto Federal de Educação, Ciência e Tecnologia de Pernambuco ainda mantém o curso em atividade na cidade do Recife, com 1.620 horas/aulas e 80 vagas. Já o início de funcionamento do curso mais recente se deu na região Sul do país, na FACID-Faculdade Integral Diferencial (no Paraná), em 20 de novembro de 2015, com 1.700 horas/aulas e 50 vagas.

No detalhamento, foi possível adquirir a data de registro no MEC de início de cada curso, além de diversas informações, como: grau, modalidade, notas no CC, CPC e ENADE, situação, data de registro, quantidade de horas/aulas, periodicidade (integralização) e número de vagas oferecidas. Foram analisados os 24 estados brasileiros e verificou-se que há cursos na área em todos os estados do país.

Para facilitar o entendimento, os dados obtidos foram computados por região do país. Os gráficos cronológicos, que apresentam o desenho em colunas na vertical, mostrando simultaneamente os nomes dos cursos por meio de cores: barras brancas (cursos denominados Desenho Industrial), barras cinza-médio (Design), barras pretas (Design Gráfico) e barras cinzaclaro com borda na cor preta (novos nomes: Design Visual e Design de Produto). Alguns nomes/cores de cursos não aparecem nos gráficos de determinadas regiões, visto que podem não existir registros deles. Cada região foi analisada separadamente, para melhor visualização dos resultados. Seguem os gráficos e tabelas dos cursos superiores tecnológicos em design no Brasil registrados no portal e-MEC:

\section{Cronologia da criação das escolas de Design Gráfico no Brasil.}

\section{Região Norte: 28 cursos}

Figura 3: Gráfico cronológico - IES - Região Norte do Brasil (composta pelos estados do Acre, Amazonas, Amapá, Rondônia, Roraima, Pará e Tocantins)

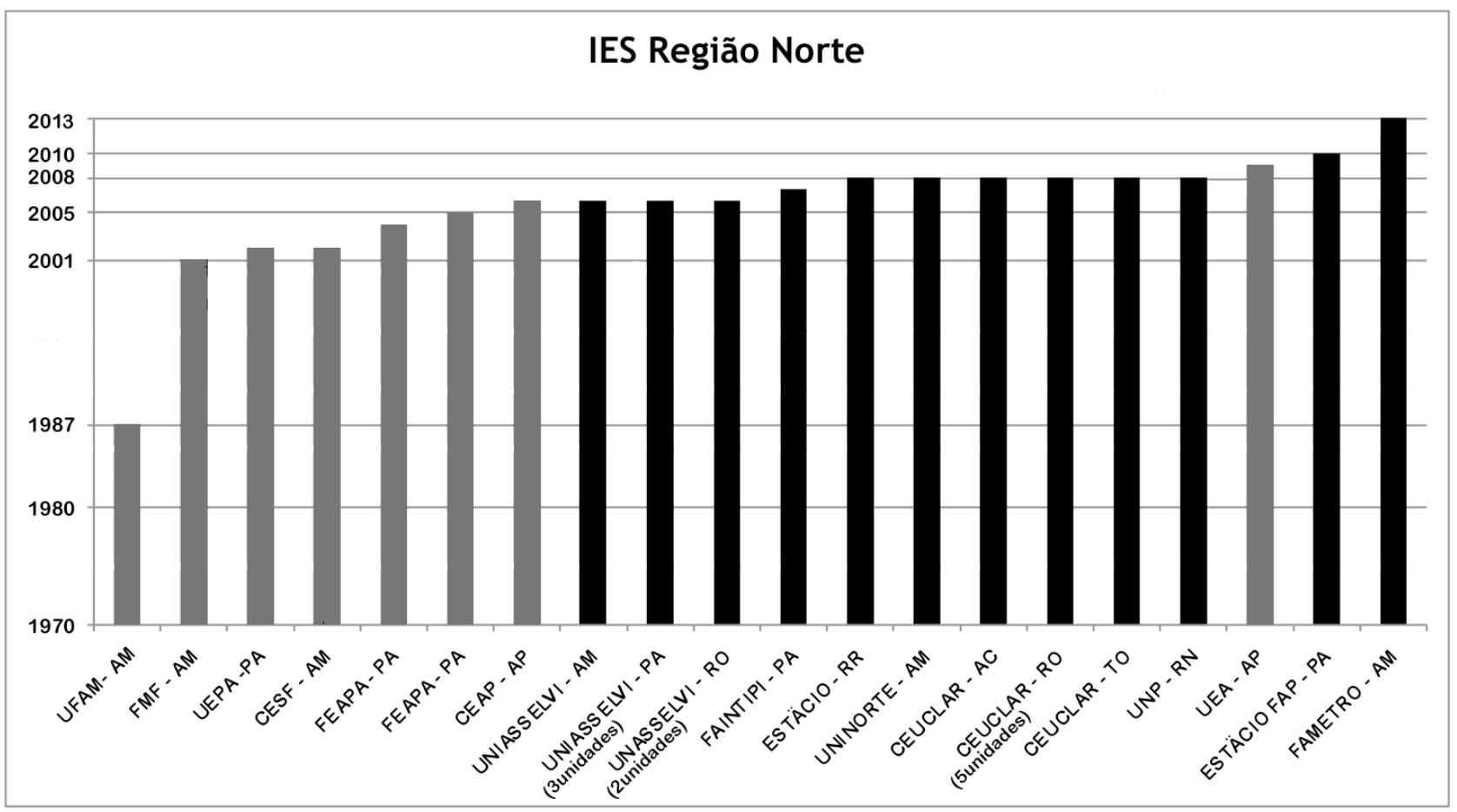

Fonte: portal do MEC. 
A Região Norte mostra prevalência sob a rubrica Design Gráfico (20 cursos) para nome de curso, assim como predominam os cursos no grau tecnológico (21 cursos). Apresenta metade na modalidade presencial (14 cursos) e metade na modalidade a distância (14 cursos). Atualmente, não há cursos registrados com o nome Desenho Industrial (o curso da UFAM-Universidade Federal do Amazonas foi extinto há alguns anos).

Região Nordeste: 52 cursos

Figura 4: Gráfico cronológico - IES - Região Nordeste do Brasil (composta pelos estados de Alagoas, Bahia, Ceará, Maranhão, Paraíba, Pernambuco, Piauí, Rio Grande do Norte e Sergipe). Todos são cursos de nome Design Gráfico, no grau tecnológico e na modalidade a distância.

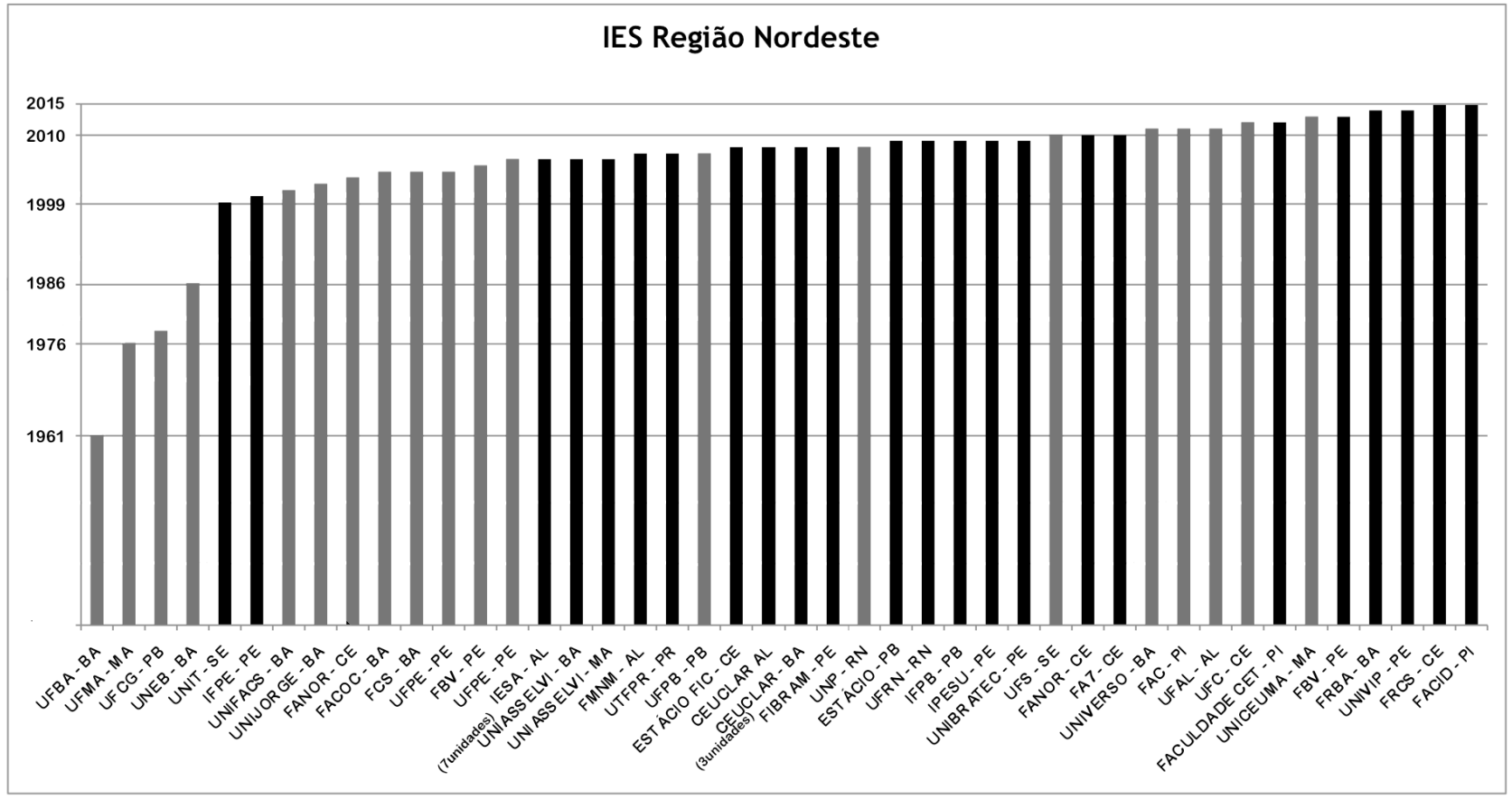

Fonte: portal do MEC.

A Região Nordeste mostra prevalência sob a rubrica Design para nome de curso de 1961 a 2000. Após este período, praticamente todos os 48 cursos foram registrados com o termo Design Gráfico. Não foi realizada uma pesquisa para averiguar se os cursos mais antigos atualizaram seu nome no registro do portal e-MEC. Não há cursos registrados como Desenho Industrial.

Percebe-se que, no período de 2011 a 2013, cinco cursos foram registrados com o termo Design, todos no grau bacharelado e na modalidade presencial. Esta região do país é a que apresenta a maior quantidade de estados (oito). No entanto, somente Ceará e Pernambuco apresentam uma quantidade bastante superior de cursos em atividade que os demais (respectivamente, sete e nove).

A Região Nordeste apresenta uma quantidade maior de cursos com o nome Design Gráfico (32 cursos) e no grau tecnológico (42 cursos), prevalecendo também a modalidade presencial (40 cursos). É a terceira região no ranking de quantidade de cursos registrados e em atividade no portal e-MEC. Possui quase o dobro de cursos ao ser comparada com as regiões Norte e Centro-Oeste, consideradas as regiões menos desenvolvidas do país. 
Região Centro-Oeste: 27 cursos

Figura 5: Gráfico cronológico - IES - Região Centro-Oeste do Brasil (composta pelos estados do Mato Grosso, Mato Grosso do Sul, Goiás e Distrito Federal).

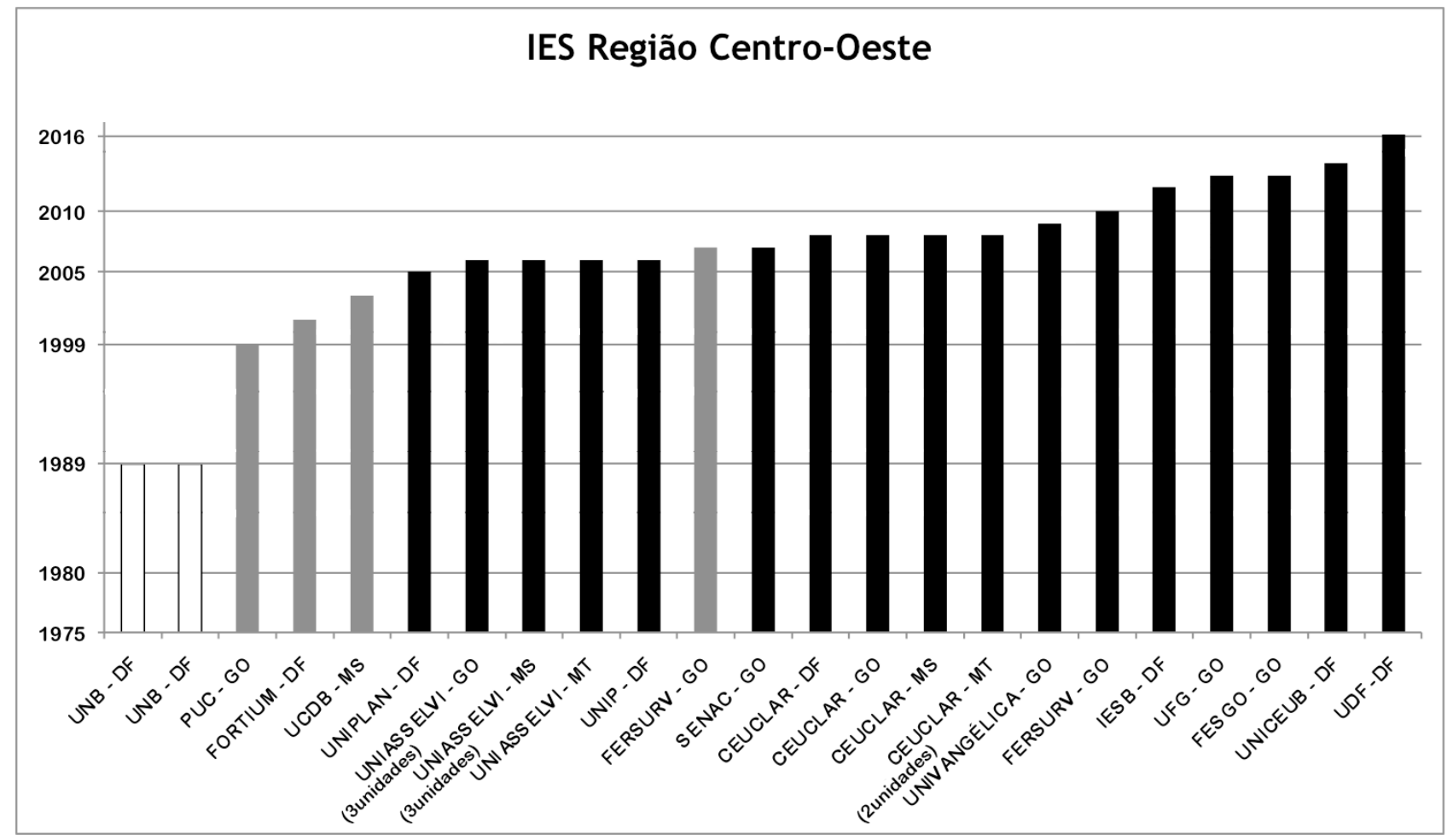

Fonte: portal do MEC.

Na Região Centro-Oeste, há prevalência sob a rubrica Design Gráfico, facilmente observada no gráfico cronológico após o ano 2005, quando ocorre, na região, o registro de 22 cursos no intervalo de apenas 10 anos.

Os cursos mais antigos registrados são da UNB-Universidade de Brasília - uma turma de Desenho Industrial-Programação Visual e outra de Desenho Industrial-Projeto de Produto - ambas no grau bacharelado (2.940 horas/aulas de curso) e na modalidade presencial, ofertando 20 vagas para cada turma.

O curso mais recente registrado é do Centro Universitário do Distrito Federal (UDF) - tratase de uma graduação tecnológica na modalidade Educação presencial, periodicidade (Integralização) semestral (4.0), carga horária de 1.600 horas e 160 vagas anuais autorizadas - data de início de funcionamento em 02/02/2016.

A Região Centro-Oeste mostra prevalência sob a rubrica Design Gráfico (21 cursos) para nome de curso, assim como predominam os cursos no grau tecnológico (21 cursos). No entanto, é importante observar que quase metade de seus cursos são na modalidade a distância (11 cursos). 
Região Sul: 96 cursos

Figura 6: Gráfico cronológico - IES - Região Sul do Brasil (composta pelos estados do Paraná, Santa Catarina e Rio Grande do Sul).

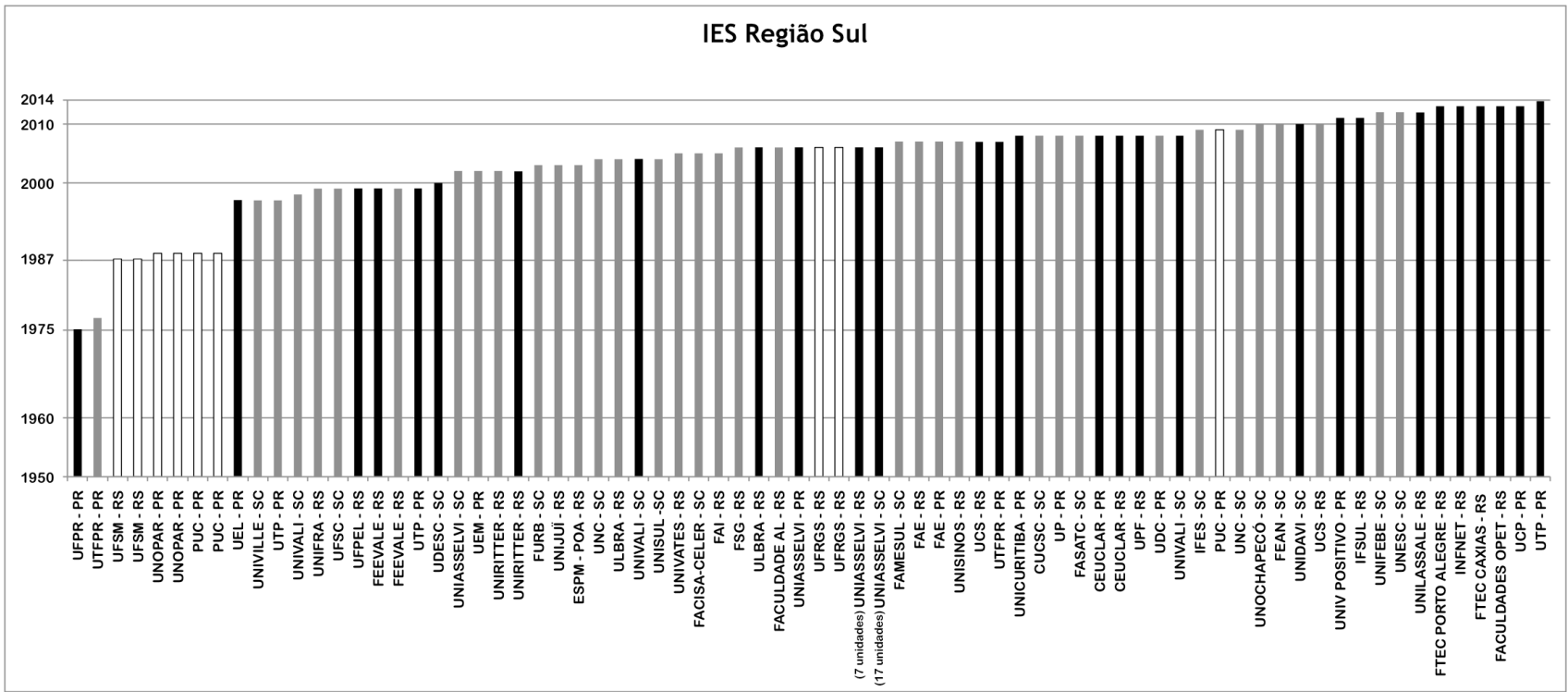

Fonte: portal do MEC.

A Região Sul apresenta-se um pouco mais complexa para análise em função da grande quantidade de cursos registrados no portal e-MEC, embora apresente o menor número de estados do país (somente três: Paraná, Santa Catarina e Rio Grande do Sul) e menor extensão territorial. É a segunda região mais desenvolvida do Brasil e a terceira mais populosa.

Ao analisar o gráfico cronológico da região, percebe-se claramente que a grande maioria dos cursos foram registrados após o ano 2.000, cerca de $82 \%$ total. Dos 15 cursos registrados nos últimos 5 anos, 10 mostram uma prevalência sob a rubrica Design Gráfico para nome de curso.

É na UFRGS-Universidade Federal do Rio Grande do Sul que se encontram os registros dos novos nomes para designar o curso na área: Design Visual e Design de Produto. Esta IES destaca-se no país em excelência por suas notas altas nos quesitos CC, CPC e ENADE.

Tabela 1: Cursos com nota Máxima: IES no cadastro e-MEC que obtiveram nota 5 no ENADE e no CPC.

\begin{tabular}{lllllc}
\hline IES & NOME DO CURSO & GRAU & CC & CPC & ENADE \\
UFRGS-UNIVERSIDADE FEDERAL DO RIO GRANDE & DESIGN VISUAL & BACHARELADO & 4 & 5 & 5 \\
$\begin{array}{l}\text { Do SUL } \\
\text { UNIVATES-CENTRO UNIVERSITÁRIO UNIVATES }\end{array}$ & DESIGN & BACHARELADO & 3 & 5 & 5 \\
\hline
\end{tabular}

Fonte: portal do MEC.

A Região Sul mostra prevalência sob a rubrica Design Gráfico (51 cursos) para nome de curso, assim como predominam os cursos no grau bacharelado (55 cursos). Contudo, a quantidade de cursos sob a rubrica Design é alta (36 cursos) e também a de cursos a distância (27 cursos). 
Região Sudeste: 154 cursos

Figura 7: Gráfico cronológico - IES - Região Sudeste do Brasil (composta pelos estados do Espírito Santo, Minas Gerais, Rio de Janeiro e São Paulo).

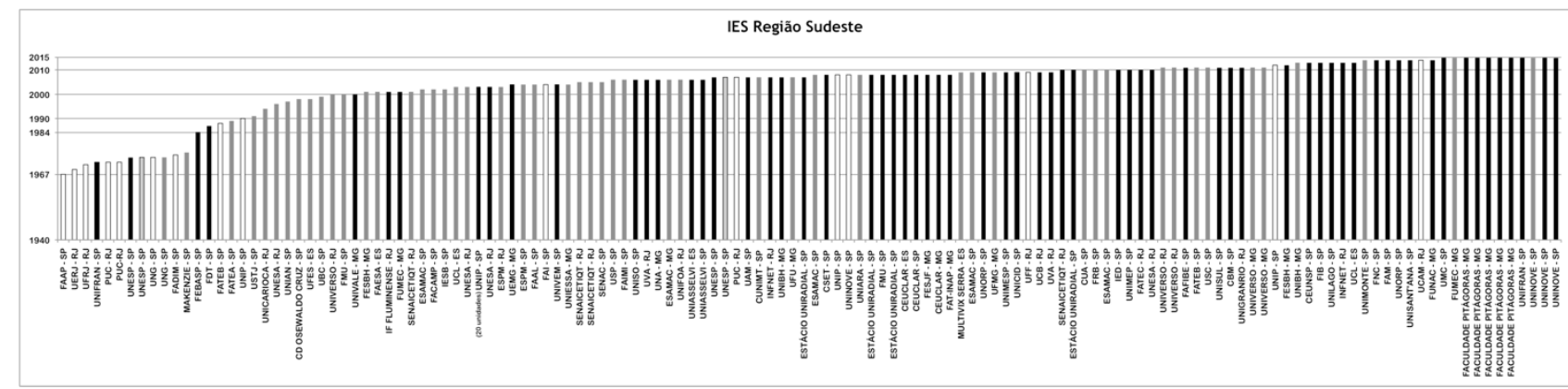

Fonte: portal do MEC.

A Região Sudeste lidera o ranking em quantidade de IES na área. $O$ estado de São Paulo tem, sozinho, mais cursos que a Região Sul do país. É a segunda menor região do Brasil (maior apenas que a Região Sul). Apresenta o maior número de cursos dentre todas as regiões, constituindo quase a metade do total (154 cursos do total de 357 cursos). Existem apenas 6 cursos na modalidade a distância.

O ensino de Design no Brasil iniciou-se em 1963, no Rio de Janeiro, mediante um Decreto baixado em 24 de dezembro de 1962, pelo então governador Carlos Lacerda, que determinou a criação da primeira escola de Design no Brasil: a Escola Superior de Desenho Industrial (FREITAS, 1999, p.1). Parte dos primeiros graduados pela ESDI foi responsável pela implantação de outros cursos de design e mais alguns passaram a integrar seus corpos docentes. Além de se tornar modelo de ensino de design no Brasil, a ESDI passou a ser um mito (NIEMEYER, 2007, p. 21).

Nesse período, surgiram mais 3 escolas de design no país, duas particulares no Rio (FACFaculdade da Cidade e FISS-Faculdades Integradas Silva e Souza) e uma pública na Paraíba (UFPB). A Escola Superior de Desenho Industrial (ESDI) foi moldada segundo a Escola de Ulm, fundada em 1953, na Alemanha - de modelo, serviram seu currículo e ideologias e de molde, seu corpo docente e modelo de ensino. Os tópicos a seguir apresentam a quantidade dos cursos em atividade na Região Sudeste, do estado com maior quantidade de cursos ao de menor quantidade:

1. São Paulo - 55 cursos em Design Gráfico, 28 cursos em Design, 8 cursos em Desenho Industrial e 2 cursos em Design de Produto. Total: 93.

2. Rio de Janeiro - 11 cursos em Design Gráfico, 12 cursos em Design e 7 cursos em Desenho Industrial. Total: 30.

3. Minas Gerais - 15 cursos em Design Gráfico e 9 cursos em Design. Total: 24.

4. Espírito Santo - 3 cursos em Design Gráfico e 4 cursos em Design. Total: 7.

A Região Sudeste manteve-se praticamente sozinha no mercado do Design por 10 anos (entre 1960 e 1970). Observa-se que o crescimento da quantidade de IES foi suave e ordenado ao longo dos anos, principalmente a partir da década de 1990. Nas demais regiões/estados do país, o crescimento da quantidade de IES foi marcante somente após o ano 2.000 - correspondendo ao final do Governo Fernando Henrique Cardoso (FHC) e início do Governo Lula. 
Figura 8: Gráfico demonstrativo das IES da Região Sudeste do país; nome dos cursos.

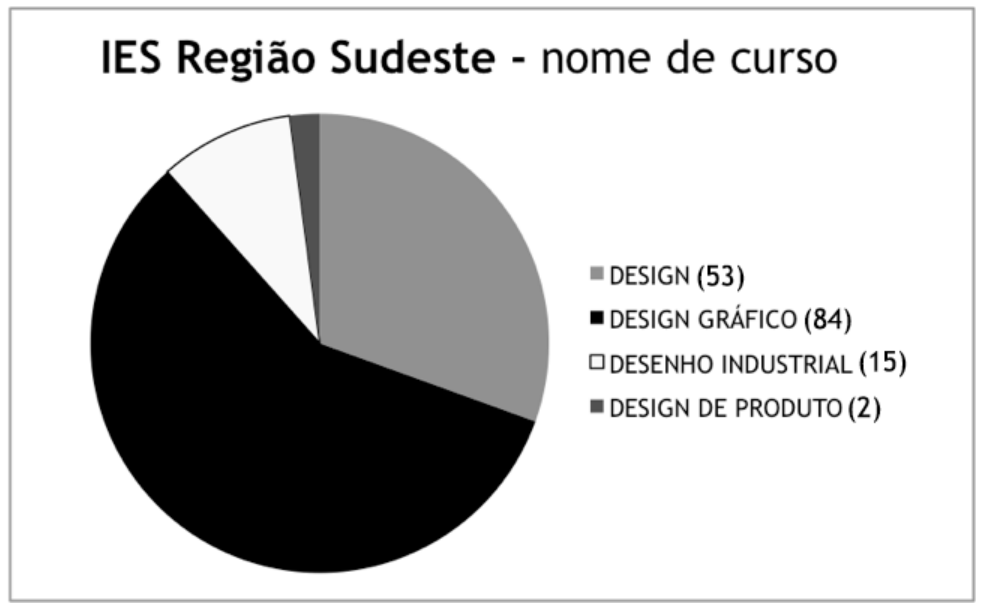

Fonte: portal do MEC.

Figura 9: Gráfico demonstrativo das IES da Região Sudeste do país; grau dos cursos.

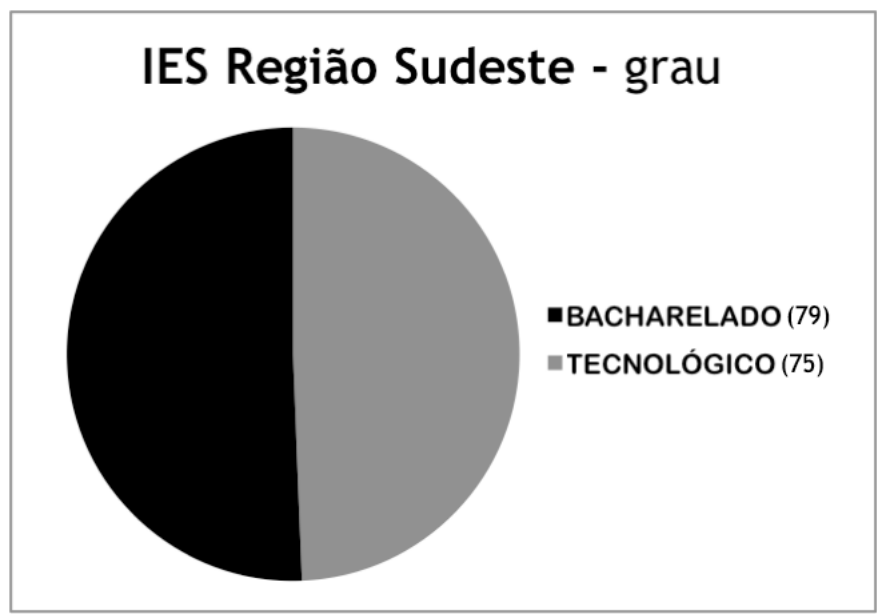

Fonte: portal do MEC.

Figura 10: Gráfico demonstrativo das IES da Região Sudeste do país; modalidade dos cursos.

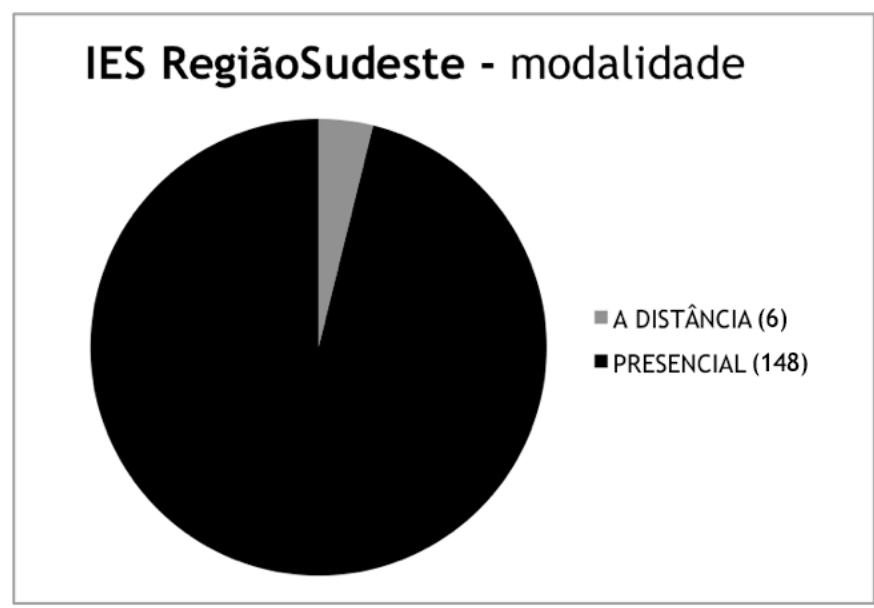

Fonte: portal do MEC. 
Como se pode observar, todas as regiões do Brasil mostram uma prevalência sob a rubrica Design Gráfico para nome de curso. Prevalecem também os cursos no grau tecnológico em quase todas as regiões, com exceção das Regiões Sudeste e Sul, a primeira apresenta diferença mínima (4 cursos), já a segunda apresenta uma diferença significativa: de 96 cursos no portal do MEC, 67 cursos são no grau bacharelado e 41 no grau tecnológico (26 cursos de diferença).

Os cursos na modalidade presencial são também uma máxima em quase todas as regiões, com exceção da Região Norte, que apresenta o registro total de 28 cursos no portal do MEC, sendo 14 presenciais e 14 a distância. Todos os cursos nesta última modalidade são no grau tecnológico.

\subsection{O Estado do Rio de Janeiro}

Rio de Janeiro: 30 cursos

Figura 11: Gráfico cronológico - IES - Estado do Rio de Janeiro.

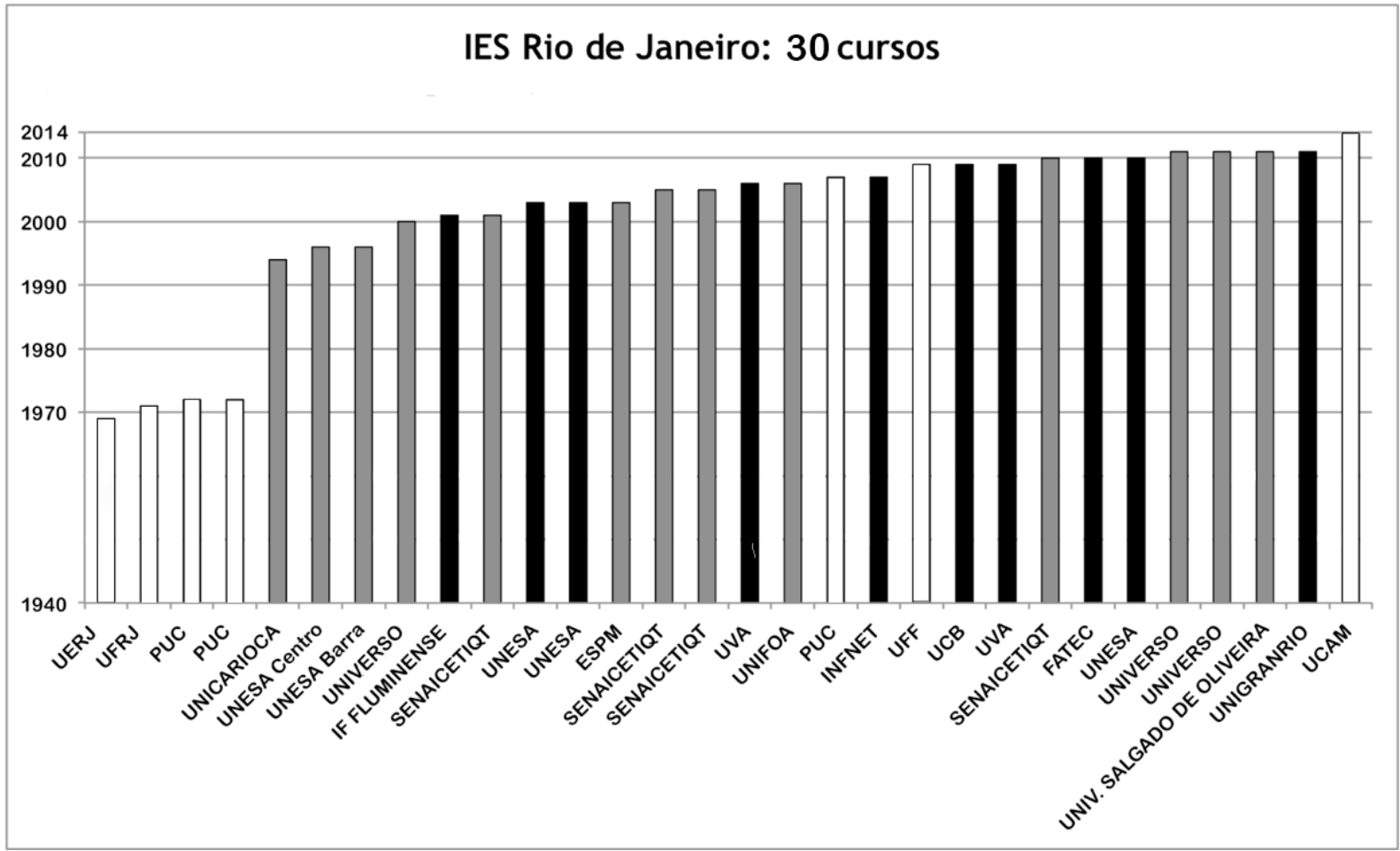

Fonte: portal do MEC.

O destaque para o estado do Rio de Janeiro na pesquisa não foi dado somente pelas informações históricas levantadas - a cidade foi pioneira na criação dos Liceus de Artes e Ofícios no Período Monárquico e da primeira IES em Design, a UERJ - mas também pela minha experiência acadêmica. Além de morar na cidade, já trabalhei como docente na Graduação e na Pós-Graduação das seguintes IES: INFNET, PUC e UVA, além de ser coordenadora atual do curso superior Tecnológico em Design Gráfico da Faculdade Tecnológica SENAC RJ.

O Rio de Janeiro apresenta todos os cursos com o nome Design Gráfico no grau tecnológico, sendo 10 na modalidade presencial e 1 a distância. Os demais, com o nome Design e Desenho Industrial, são no grau bacharelado. 
Segue a Tabela Cronológica (2001-2016) do Estado do Rio de Janeiro das IES tecnológicas registradas no MEC já com a coluna da nota alcançada pelos cursos no ENADE 2015, resultado obtido no site do INEP, em 03 de Março de 2017:

Tabela 2: IES Tecnológicas do estado do Rio de Janeiro em ordem cronológica de registro no Portal do MEC. Obs.: a quantidade de vagas da IES FATEC foi atualizada nessa tabela

\begin{tabular}{|c|c|c|c|c|c|c|c|c|}
\hline ANO & UF & IES & $\begin{array}{l}\text { NOME DO } \\
\text { CURSO }\end{array}$ & GRAU & HS & MODALIDADE & VAGAS & ENADE \\
\hline 2001 & RJ & $\begin{array}{l}\text { IF FLUMINENSE- } \\
\text { INSTITUTO FEDERAL DE } \\
\text { EDUCAÇÃO, CIÊNCIA E } \\
\text { TECNOLOGIA FLUMINENSE }\end{array}$ & $\begin{array}{l}\text { DESIGN } \\
\text { GRÁFICO }\end{array}$ & BACHARELADO & 2.116 & PRESENCIAL & 60 & 4 \\
\hline 2003 & RJ & $\begin{array}{l}\text { UNESA-UNIVERSIDADE } \\
\text { ESTÁCIO DE SÁ }\end{array}$ & $\begin{array}{l}\text { DESIGN } \\
\text { GRÁFICO }\end{array}$ & BACHARELADO & 1.776 & PRESENCIAL & 280 & 3 \\
\hline 2003 & RJ & $\begin{array}{l}\text { UNESA-UNIVERSIDADE } \\
\text { ESTÁCIO DE SÁ }\end{array}$ & $\begin{array}{l}\text { DESIGN } \\
\text { GRÁFICO }\end{array}$ & BACHARELADO & 1.776 & PRESENCIAL & 280 & 3 \\
\hline 2006 & RJ & $\begin{array}{l}\text { UVA-UNIVERSIDADE } \\
\text { VEIGA DE ALMEIDA }\end{array}$ & $\begin{array}{l}\text { DESIGN } \\
\text { GRÁFICO }\end{array}$ & BACHARELADO & 1.600 & PRESENCIAL & 180 & 2 \\
\hline 2007 & RJ & $\begin{array}{l}\text { INFNET-INSTITUTO } \\
\text { INFNET RIO DE JANEIRO }\end{array}$ & $\begin{array}{l}\text { DESIGN } \\
\text { GRÁFICO }\end{array}$ & BACHARELADO & 2.182 & PRESENCIAL & 100 & 4 \\
\hline 2009 & RJ & $\begin{array}{l}\text { UCB-UNIVERSIDADE } \\
\text { CASTELO BRANCO }\end{array}$ & $\begin{array}{l}\text { DESIGN } \\
\text { GRÁFICO }\end{array}$ & TECNOLÓGICO & 1.840 & PRESENCIAL & 160 & 2 \\
\hline 2009 & RJ & $\begin{array}{l}\text { UVA-UNIVERSIDADE } \\
\text { VEIGA DE ALMEIDA }\end{array}$ & $\begin{array}{l}\text { DESIGN } \\
\text { GRÁFICO }\end{array}$ & TECNOLÓGICO & 1.600 & PRESENCIAL & 180 & 3 \\
\hline 2010 & RJ & $\begin{array}{l}\text { FATEC-FACULDADE DE } \\
\text { TECNOLOGIA SENAC RJ }\end{array}$ & $\begin{array}{l}\text { DESIGN } \\
\text { GRÁFICO }\end{array}$ & TECNOLÓGICO & 1.600 & PRESENCIAL & 140 & 3 \\
\hline 2010 & RJ & $\begin{array}{l}\text { UNESA-UNIVERSIDADE } \\
\text { ESTÁCIO DE SÁ }\end{array}$ & $\begin{array}{l}\text { DESIGN } \\
\text { GRÁFICO }\end{array}$ & BACHARELADO & 1.776 & PRESENCIAL & 80 & \\
\hline 2011 & RJ & $\begin{array}{l}\text { UNIGRANRIO- } \\
\text { UNIVERSIDADE DO GRANDE } \\
\text { RIO PROFESSOR JOSÉ DE } \\
\text { SOUZA HERDY }\end{array}$ & $\begin{array}{l}\text { DESIGN } \\
\text { GRÁFICO }\end{array}$ & BACHARELADO & 1.760 & PRESENCIAL & 100 & 2 \\
\hline 2013 & RJ & $\begin{array}{l}\text { INFNET-INSTITUTO } \\
\text { INFNET RIO DE JANEIRO }\end{array}$ & $\begin{array}{l}\text { DESIGN } \\
\text { GRÁFICO }\end{array}$ & BACHARELADO & 2.182 & À DISTÂNCIA & 500 & - \\
\hline
\end{tabular}

Fonte: portal do MEC.

Verifica-se que o crescimento da quantidade de IES tecnológicas foi suave ao longo dos anos 2.000. Há um equilíbrio em quantidade de cursos em relação ao grau. $E$, merece destaque, o fato de todos os cursos serem registrados com o nome Design Gráfico.

Pode-se observar que as graduações tecnológicas em Design Gráfico do IF Fluminense e do INFNET possuem maiores quantidades de horas/aulas que os demais cursos. Ambos têm a carga horária mínima exigida, porém sua formação completa-se em três anos com a periodicidade (integralização) do primeiro sendo semestral (6.0) e a do segundo trimestral (12.0). As maiores notas no ENADE foram, justamente, destes cursos de maior duração.

Segue o gráfico-pizza para melhor visualização da informação sobre o grau dos cursos nas IES cariocas: 
Figura 12: Gráfico demonstrativo das IES do Estado do Rio de Janeiro; grau dos cursos.

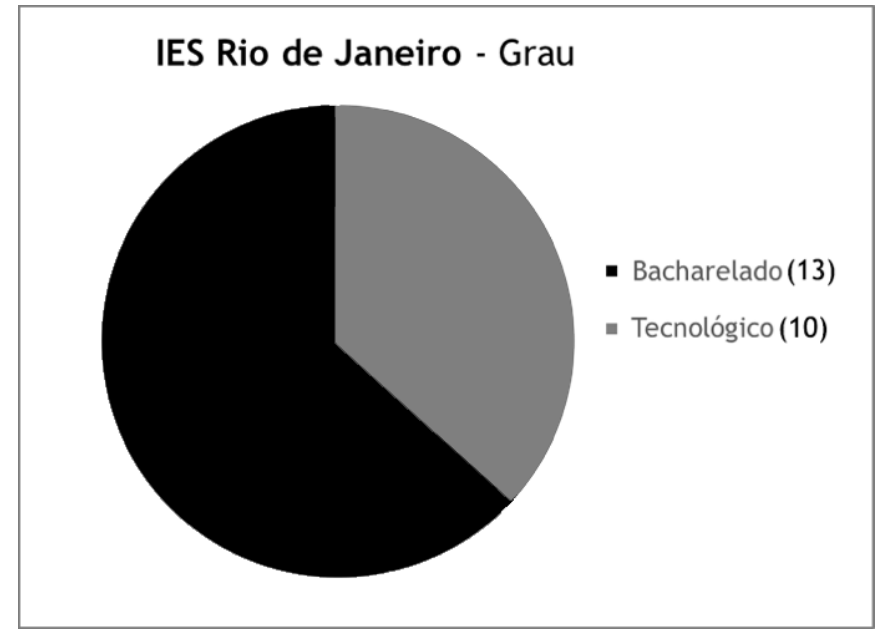

Fonte: portal do MEC.

Os 11 cursos em Design Gráfico do estado do Rio de Janeiro são no grau tecnológico, sendo 10 na modalidade presencial e 1 a distância. Os cursos de nome Design (12 cursos) e os de nome Desenho Industrial (7 cursos) são no grau bacharelado e na modalidade presencial.

\section{Conclusão}

Conclui-se que a quantidade de cursos superiores tecnológicos em Design aumentou muito nos últimos anos e que a área se segmentou para públicos distintos. Foram identificadas $\mathbf{1 0 0}$ instituições no Brasil, oferecendo um total de 156 cursos superiores em Design, Design Gráfico e/ou Desenho Industrial somente na Região Sudeste do país.

Como se pode observar, todas as regiões do Brasil mostram uma prevalência sob a rubrica Design Gráfico para nome de curso. Prevalecem também os cursos no grau tecnológico em quase todas as regiões, com exceção das Regiões Sul e Sudeste.

Este artigo é um recorte da tese intitulada "Cursos superiores de graduação tecnológica em design: expansão e contexto atual da oferta no Brasil" (2017) que, para o levantamento dos dados, utilizou-se dos seguintes procedimentos: Pesquisa bibliográfica, Pesquisa documental, Seminário e Entrevistas Semiestruturadas realizadas com os coordenadores de cursos superiores tecnológicos em Design do Estado do Rio de Janeiro. Destaca-se aqui uma das dez perguntas de opinião sobre a quantidade de cursos existentes nas modalidades bacharelado, tecnológico, licenciatura e sequencial no Brasil: todos os coordenadores cariocas se equivocaram ao desenhar num gráficopizza a quantidade de cursos existentes de cada grau. Foi unânime a surpresa sobre a quantidade de cursos tecnológicos existentes, dados apresentados ao final das entrevistas; os coordenadores não conheciam os dados reais da quantidade dos cursos. O crescimento da quantidade de IES foi rápido e elevado, causando surpresa aos coordenadores de curso das graduações tecnológicas em Design Gráfico do Rio de Janeiro.

A evolução histórica da Educação no Brasil mostra que os Liceus, as Escolas Técnicas, CEFETS etc, sempre formaram para um mercado de trabalho com este perfil de profissional. Percebe-se esforço dos governos com os órgãos que regulam o ensino superior no país, em categorizar e configurar as IES que oferecem cursos na área. Entretanto, o portal e-MEC ainda é muito frágil para 
constituir a única fonte de informações que disponibiliza esses dados. A ferramenta desenvolvida para o sistema de acesso ao público é ineficiente e, muitas vezes, deixa o pesquisador sem as informações atualizadas sobre dados importantes. Recomenda-se que os dados sobre as IES e cursos (códigos, modalidade, grau, nome, UF, Município, ENADE, CPC e CC, data de início de funcionamento, carga horária, coordenador, situação de funcionamento, periodicidade, vagas anuais, etc) sejam disponibilizados e auxiliem com essas informações.

Ainda tornam-se necessários muitos estudos sobre a estrutura das IES tecnológicas de Design, perfil do aluno tecnólogo, inserção no mercado de trabalho, perfil dos coordenadores de cursos e professores, habilitações em Design e Indicadores de Qualidade (INEP). Só serão construídos referenciais que permitam a definição de ações voltadas à melhoria da qualidade dos cursos de graduação tecnológica por parte dos coordenadores, professores, dirigentes e autoridades educacionais se forem feitas mais pesquisas sobre o assunto.

\section{Referências}

CATÁLOGO NACIONAL DE CURSOS SUPERIORES DE TECNOLOGIA $3^{\text {a }}$ Edição. República Federativa do Brasil - Ministério da Educação - Secretaria de Regulação e Supervisão da Educação Superior Secretaria de Educação Profissional e Tecnológica. Brasília/DF, 2016.

CERVO, A. Metodologia Científica. São Paulo: Pearson Prentice Hall, 2007.

FAVRETTO, J. Cursos Superiores de Tecnologia: surgimento, legislação e expansão no período pós-LDB. 2010. Dissertação (Mestrado em Educação ) - Programa de Pós-graduação em Educação, Universidade de Passo Fundo, Rio Grande do Sul.

FREITAS, S. A Influência de tradições acríticas no processo de estruturação do ensino/pesquisa de Design. 1999. 429f. Tese (Doutorado em Engenharia de Produção) - Programa de Pósgraduação em Engenharia, Universidade Federal do Rio de Janeiro, Rio de Janeiro.

PORTAL MEC. Carga Horária. Disponível em: $<$ http://portal.mec.gov.br/conselho-nacional-de-educacao/atos-normativos--sumulas-parecerese-resolucoes?id=12801>. Acesso em: 20/03/2016.

PORTAL DO MEC. E-MEC - Consulta interativa e consulta textual. Disponível em: <http://emec.mec.gov.br/>. Acesso em: 20/03/2016.

NIEMEYER, L. Design no Brasil: Origens e instalação. Rio de Janeiro: 2AB, 2007.

PROJETO PEDAGÓgICO DE CURSO. Curso Superior de Tecnologia em Design Gráfico - Eixo Tecnológico: Produção Cultural e Design. Código Senac Rio: 11062. Código DN: 734. Reconhecido pelo MEC/SERES sob no 134 em 27/07/2012. Graduação Tecnológica em Design Gráfico.

SCHNAIDER, S. H. de C. Cursos superiores de graduação tecnológica em design: expansão e contexto atual da oferta no Brasil. 2017. 153f. T Tese (Doutorado em Design) - Programa de Pósgraduação em Design, Universidade Estadual "1l do Rio de Janeiro, Rio de Janeiro.

WITTER, G. Desenho Industrial - Uma perspectiva Educacional. São Paulo: CNPq/Coordenação Editorial, 1985. 